\title{
The Assessment of the Sound Environment in the Workplace: A Lever for Work Quality and Safety
}

\author{
Nadira MAAMRI \\ Université Frères Mentouri, Constantine 1, Algeria, nadira_maamri@yahoo.fr \\ Rachid CHAIB \\ Université Frères Mentouri, Constantine 1, Algeria, r3chaib@yahoo.fr \\ Mohamed BENIDIR \\ Université Frères Mentouri, Constantine 1, Algeria, mcbenidir@yahoo.fr \\ Ion VERZEA \\ “Gheorghe Asachi” Technical University, Iasi 700050, Romania, verzea2000@yahoo.com
}

\begin{abstract}
The Noise is an essential component the living environment and working environment except but it constitutes a major nuisance in the professional environment. Exposure to noise in an excessive manner can have adverse effects on the health and safety of workers. The exposure, despite its short duration, is dangerous and can generate for the employee different psychological, physical, behavioral and economic consequences. It can lead to deafness, an irreversible phenomenon. In addition to hearing loss and tinnitus, it is recognized as an initiator of fatigue, physical and psychological stress, decreased attention, concentration and leads to a decline in cognitive performance, or even consequences on the health of the employee and the quality of his work: a drop in productivity and an increase in absenteeism. Moreover, occupational exposure to noise accelerates the process of acquiring presbycusis. This results in human, social and economic costs for the company. As a result, it becomes essential to manage and prevent noise nuisance in companies, objectives of the work. This work aims at evaluating the risks due to noise pollution at a drilling site of the ENAFOR Company, or even manages to draw the sound map of the site. The latter, allows identifying places and workstations most exposed to sound hazards. A questionnaire has also been used in order to identify the impact of noise pollution on the workers and the link with the mapped cartography, or even establish the necessary preventive measures.
\end{abstract}

\section{Keywords}

Assessment, risk, noise pollution, prevention, psycho sociological facts, sound mapping

\section{Introduction}

In most industrial sectors the noise is a determining factor in the work situation, the health of staff and the company performance [1]. It is considered to be one of the most frequent and threatening pollutants in the sound environment. Ranked fourth on the scale of environmental pollution, the noise continues to take alarming dimensions and sometimes becomes a real obsession [2]. Today, attacks manifested in health continue to affect a large number of employees and the incidence of recognized occupational diseases is increasing alarmingly [3, 4]. Now the environment is subject to apprehension and still major concerns, one aspect of which is still its biggest enlargement to the health and well-being are closely linked together [5]. Therefore, organizations must be able to fight against the problems that arise in terms of safety and health at work or respond effectively in dynamic management strategies [6]. Therefore, it is important to remember that preventive medicine is based primarily on the recognized role of the environment as a determinant of health and environmental health aims at preventing environmental diseases and create a favorable environment to health.

A quarter of the world's deaths are said to be attributable to an unhealthy environment. Among these healthiness, noise is a real scourge, recognized as a cause of the most expensive occupational disease and represents a source of discomfort at various levels and in all activity areas. It is a real threat to take seriously at work. It is serious by its irreversible nature and by its inevitable evolution towards the handicap with all its social and professional health impacts [2]. For instance, in Germany 4 to 5 million people (12 to $15 \%$ of the active population) are exposed to noise levels defined as hazardous by the 
World Health Organization (WHO, 1991) [7]. In the United States, some 30 million workers are exposed to potentially hazardous noise levels at work (NIOSH, 2006) [8]. Now, the estimation of the risks incurred, consequences in term of human damages and/or costs induced, for the present and for the future, as well as the implementation of safety devices allowing to foresee, to prevent or to manage these harmful effects, which can be: direct biological and physiological hearing effects: (hearing fatigue or transient deafness) or definitive; indirect biological and extra-auditory effects concerning well-being, in particular the central nervous system (sleep disorders, etc.), psyche (performance, concentration, nervousness, aggressiveness, etc.) and the neurovegetative system (blood pressure, blood supply, heart rate, digestive system, metabolism, "stress reactions", etc.), stress, sleep disorder, etc. $[9,10,11]$, what makes prevention the object of a strong societal demand.

The work objective is the sound level evaluation at work within the framework of current legislation in order to determine the appropriate means to ensure the safety of workplaces. As fields of application, the Algerian national drilling company (drilling site) was chosen.

The proposed work methodology consists of two main parts: the tracing of sound mapping by in situ measurements and its crossing with the data of the population questioned on the same site in order to quantify the exposed employees.

\section{Presentation of the Study Area}

The Company concerned by the study is the Algerian national drilling company ENAFOR-Hassi Messaoud. The main activities of the company are drilling and Work-Over, meaning research, discovery and extraction of hydrocarbons in the desert areas of Algeria which are famous for their different natural resources (oil, natural gas, coal ...). The study is carried out at the drilling site where employees work in general 12 hours a day for 6 days of the week (32 hours per week). Since the employees spend most of the time at work, expectations in terms of life quality are therefore important. Henceforth, the daily exposure to the risk of noise affects their health, their performance and their social life.

\section{Method and Material}

The proposed methodology of work consists of two parts, namely:

- Direct measurement in situ to trace the sound map of the site. The essential measuring equipment used is the sound level meter (micro + electronic assembly, type: IEC 61672 II, S/N: 131202688). Measurements are made at a distance of more than $1 \mathrm{~m}$ from the sound source to estimate the noise level to which workers are exposed, see Figure 1. This noise mapping allows establishing by modeling a precise diagnosis of noise levels per workstation and to evaluate the impact on employees according to hourly periods. In addition to being a knowledge tool, the noise map is also a forecasting tool.

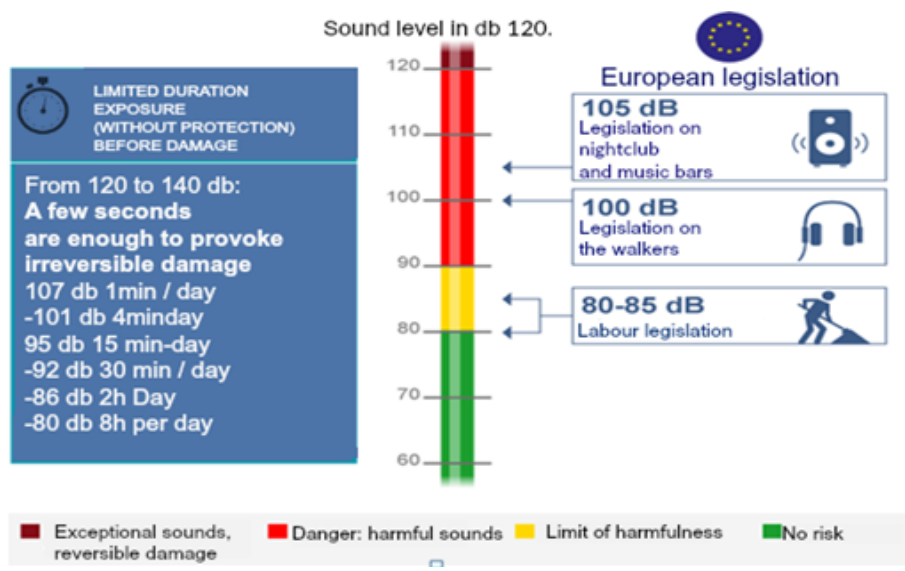

Fig 1. The level/duration relationship (directive $n^{\circ} 2003 / 10 / C E$ )

- A questionnaire to identify the impact of noise pollution on the health of employees and the link with sound mapping has been drawn. The questionnaire consists of well-formed questions to get 
essential information about the effects of sound pollution spread through the site considered. It consists of 16 main questions in relation to the subject of the survey (Appendix 1). The identification of its effects favors the implementation of appropriate prevention and protection measures. The questionnaire is one of three major methods for studying psycho sociological facts. It is a method of collecting information in order to understand and explain the facts. This quantitative tool applies to a sample that must allow statistical inferences.

The tool used for processing the questionnaire is SPSS software [13]. The latter is designed for statistical processing in social sciences (Statistical Package for Social Sciences).

\section{Results and Discussion}

\subsection{Measurement results}

According to the international standard ISO 9612:2009, the Executive Decree $\mathrm{n}^{\circ}$ 91-05 of 19 January 1991 concerning the protection requirements applicable to health and safety at the workplace, as well as the Executive Decree ${ }^{\circ}$ 93-184 of 27 July 1993 comprising regulations of noise emissions. The measurement of noise levels at the workplace and the implementation of necessary corrections are mandatory in order to reduce the risks to a tolerable level or even improve the quality of the sound environment. According to the INRS, "being exposed for 8 hours at $80 \mathrm{~dB}(\mathrm{~A})$ is as dangerous as being exposed for 1 hour at $89 \mathrm{~dB}(\mathrm{~A})$ ". Table 1 shows the sound levels that were measured at the company involved in the study. The measurement points were chosen according to the noise pollution of the equipment and the grouping of the exposed workers. The values included in the table represent an average of three (03) maximum values, each measurement lasts at least 05 minutes in order to cover the possible variations. These measurements have allowed drawing the sound maps of the building sites, see Figure 2.

Table 1. Noise levels measured at the drill site

\begin{tabular}{|c|c|c|c|}
\hline $\mathbf{N}^{\circ}$ & Location & Exact location/equipment & Value (dB) \\
\hline \multirow[t]{4}{*}{1} & MINI-CAMP & Offices & 63 \\
\hline & & Rooms & 60 \\
\hline & & Restaurant A & 60 \\
\hline & & Restaurant B & 60 \\
\hline \multirow[t]{3}{*}{2} & FLOOR & Between the hole Rotation Table and Winch & 91 \\
\hline & & Sounder master cabin & 92 \\
\hline & & Cabestan & 93 \\
\hline \multirow[t]{3}{*}{3} & Caterpillar & Point/emptying & 104 \\
\hline & Generator & Point/Blowing & 104 \\
\hline & & Generator & 103 \\
\hline 4 & SCR Room & SCR Room & 78 \\
\hline \multirow[t]{3}{*}{5} & SUBSTRUCTUR & Cave & 88 \\
\hline & $\mathbf{E}$ & Inclined plane & 90 \\
\hline & & Manifold & 92 \\
\hline \multirow[t]{4}{*}{6} & MUD BINS & Vibrating screen & 93 \\
\hline & & Agitator & 91 \\
\hline & & Degasser & 90 \\
\hline & & Catchy cabin & 93 \\
\hline \multirow[t]{3}{*}{7} & SLUDGE PUMPS & Between the two pumps & 87 \\
\hline & & Between and sup/charging and pumps & 88 \\
\hline & & Between the substructure and pump & 87 \\
\hline \multirow[t]{5}{*}{8} & WORKSHOPS & Mechanical workshop & 87 \\
\hline & & Electrical workshop & 88 \\
\hline & & Welding workshop & 87 \\
\hline & & Fixed grindstone & 86 \\
\hline & & Chain saw & 86 \\
\hline
\end{tabular}




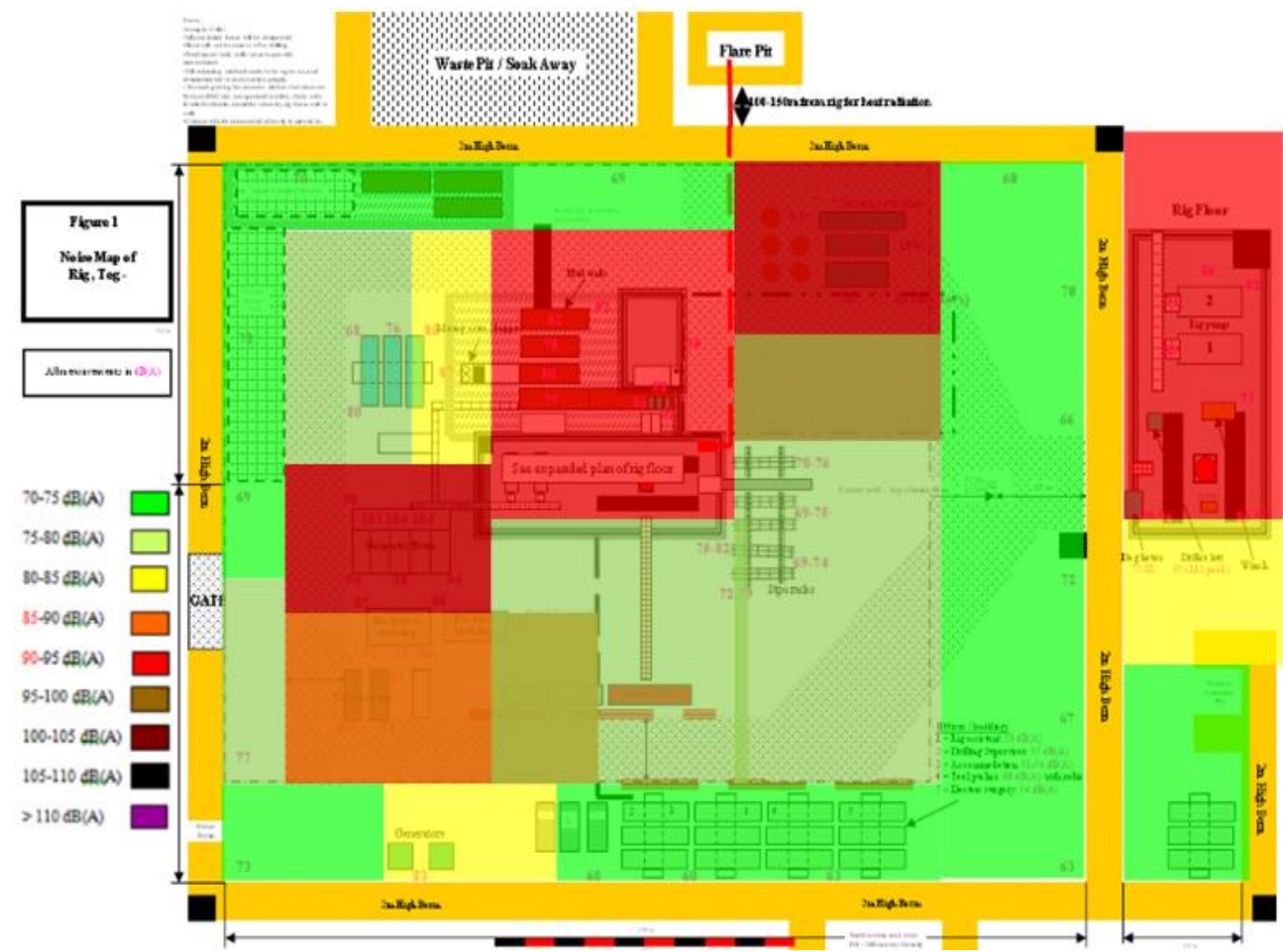

Fig. 2. Sound mapping of the drilling site

Noise levels measured in the drill site exceed the warning sound level ( $85 \mathrm{~dB})$ in the majority of workstations 13. Similarly the dangerous level $90 \mathrm{~dB}$ is thus exceeded especially at the drilling platform. The latter has an essential work area and passage. It is also noted that the area most exposed to noise over $(103 \mathrm{~dB})$ is that which contains the generator. Now, with 12 work hours and a noise level exceeding the threshold, the quality of the work environment is unhealthy and as a result the health and quality of work are impaired. The noise level is high especially with a 12 work hours. Special attention is required and occupational health must intervene to protect the work environment and to identify occupational hazards. Thus, ensuring the safety and security of the working environment. Now, a strong and productive economy cannot be achieved without proper hygiene and safety standards.

So as the study to be confirmed and to know the attitude of the employees a questionnaire was formulated and distributed to the workers.

\subsection{Questionnaire Results}

The questionnaire was distributed on the drilling sites (morning and night teams). From the 72 workers on the site, 57 responded to this questionnaire. The results of the questionnaire-based survey and the noise impact on employee health are detailed further on.

The structure of the sample used for the questionnaire can be broken down by the respondents' position (an average of 03 persons by position responded to the questionnaire, as shown in Figure 3), years of service length (Figure 4), age group (Figure 5), and daily exposure to noise.

The state of workers' hearing in relation to seniority is shown in Figure 7.

The majority of workers are exposed to more than 8 hours of noise pollution in an order of magnitude of $74 \%$.

It can be noted that hearing state 'bad' is the most dominant. It affects the population with the greatest service length (seniority factor), but compared to the average hearing status seniority, the more affected is the category that have between 5 to 10 years of service length. In this case, the position criterion needs be taken into consideration: the position most exposed to noise risk.

Figure 8 shows the effects of noise on employee health. 


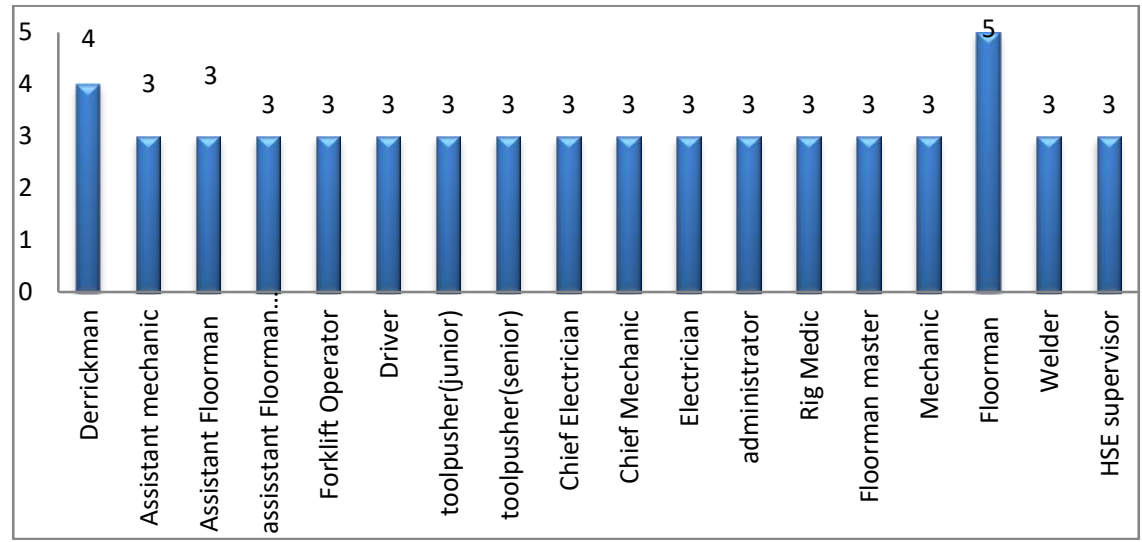

Fig. 3. The population targeted by the questionnaire

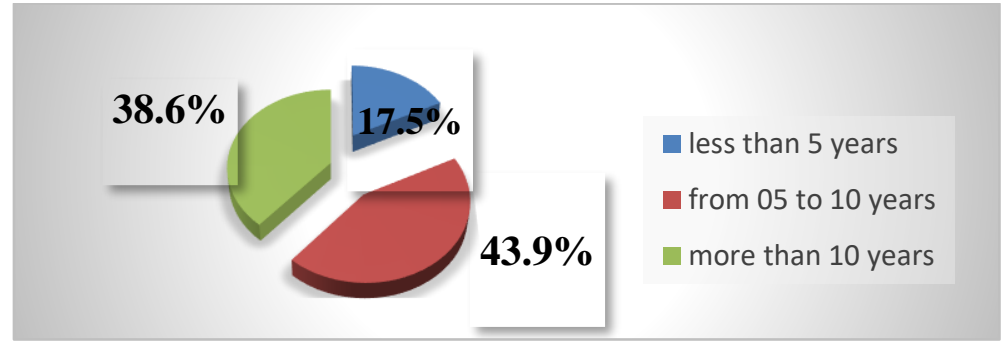

Fig. 4. Population distribution by service length

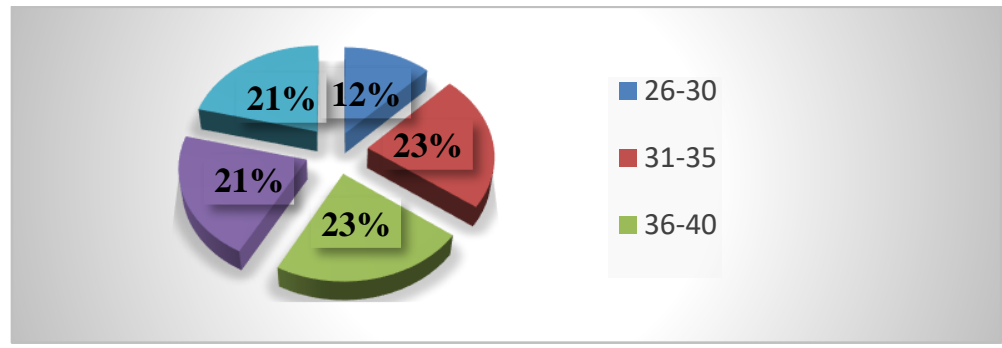

Fig. 5. Population distribution by age group

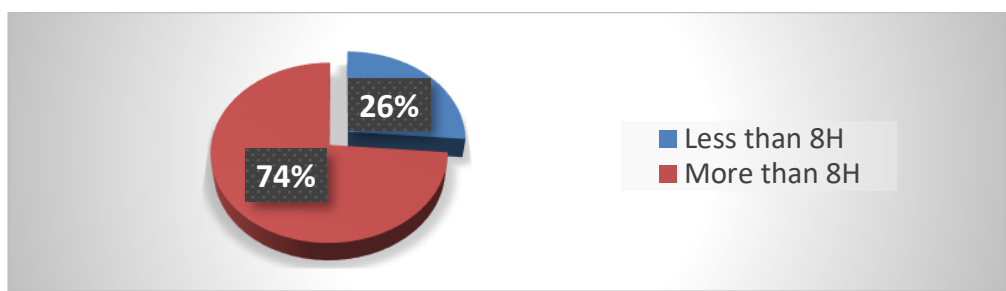

Fig. 6. The daily exposure of employees to noise

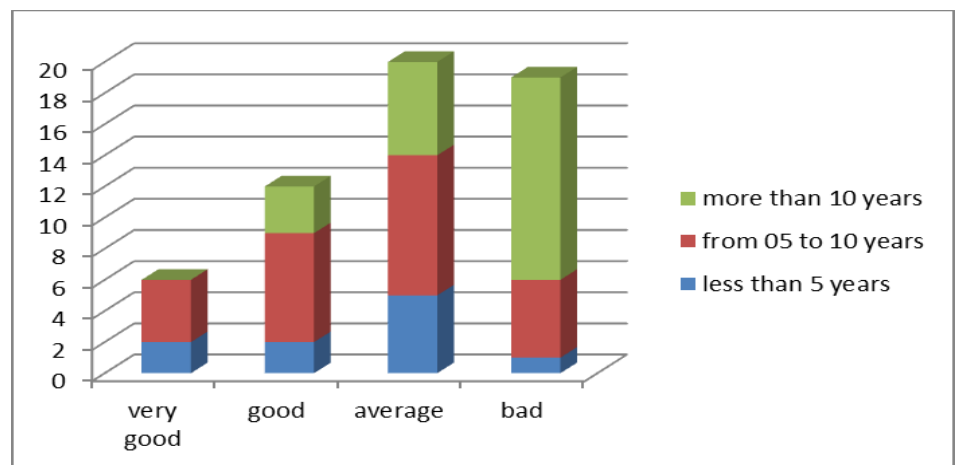

Fig. 7. The state of workers' hearing by seniority 


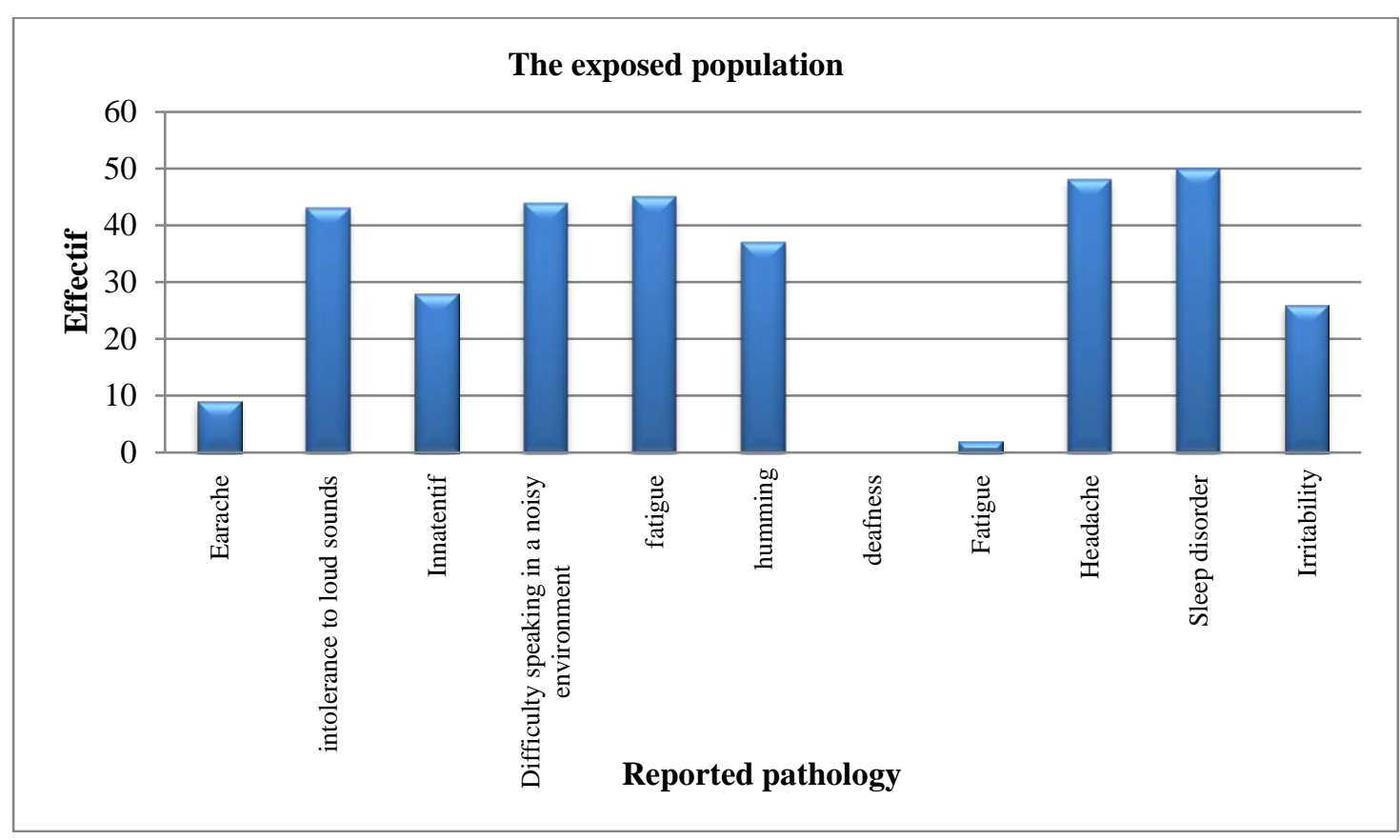

Fig. 8. The effects of noise on employee health

The work environment is generally noisy. The most affected employees according to the questionnaire are persons with the longest service length in the field, especially those working on the floor (Floorman, Derrickman, Assistant Floorman, ...). The majority of employees suffer from sleep disorders $84 \%$, headaches $87 \%$, fatigue $78 \%$ and communication difficulties $77 \%$. The occurrence of deafness as an effect is nil, however the appearance of effects such as $64 \%$ humming, $33 \%$ earache, $43 \%$ intolerance to loud sounds, $3 \%$ vertigo are reported. This situation calls for, possibly even requires imperatively the strengthening of safety measures. All these disturbances in the work environment influence well-being at work, favour human error through the lack of concentration and difficulties in communication that affect the quality of work.

Therefore, it is essential to develop specific policies for the various areas of activity areas such as to consider not only the impact on the environment but also on health, as deafness can be induced or aggravated by chemicals, ototoxic and biological agents and certain drugs. Further and importantly a legal framework for noise management is needed.

\section{Conclusion and recommendations}

Sound measurements are mandatory if the regulatory threshold is exceeded and safety measures are required. A noise management plan that includes noise monitoring, exposure mapping, and methods to address this threat is needed, while focusing on the most important sources. Henceforth, the employee's health is a top priority at all levels. It is therefore essential to develop policies in the various activity areas that take into account their impacts not only on the environment but also on health. If the environment and health are simple-looking concepts, it is clear that the ins and outs (dangers / risks / consequences) of this relationship are extremely complex and a brief overview of this complexity is worthy of note. Therefore, it is essential to prevent and correct environmental nuisances that can cause disorders or diseases hence the slogan of the WHO «The environment of today is tomorrow's health». In addition, the occupational health function must be conferred in predictive value.

Our recommendations are:

- Encouraging measures for the health and well-being at work through the implementation of corrective actions, primarily by collective preventive measures, complemented by individual preventive measures if necessary;

- Keep workers away, at least for part of the day, from the noisiest areas;

- Hold sensitization and motivation sessions for workers on the risks related to noise exposure; 
- Understanding the working conditions, organizational culture or management styles, all likely to be motivational or demotivating factors of employees, allows to enter a systemic and global logic of the company development, whose first capital remains the human;

- The use of hearing protection devices (PICB) must be mandatory for all exposed employees;

- The periodic medical examination is essential especially to the categories most exposed to the sound risks (sounder, catchy ...);

- Developing the research production and knowledge in occupational health in durability conditions, visibility and scientific rigor, and to ensure its operational dissemination, to companies and their employees. Thus, a more global approach is needed, where the employee with his work environment is part of a system that influences his motivation, attitudes, behaviors, health and performance.

\section{References}

1. Ondet A.-M., Mondot J.-M.: Évaluer l'exposition des travailleurs au bruit. Acoustique et technique $\mathrm{n}^{\circ} 12$, De la crèche ... à l'usine. Available at: http://www.bruit.fr/revues/78 09484.PDF. Accessed: 2018-05-15

2. ***: Plan National de la Prévention des Accidents de Travail et des Maladies Professionnelles. Guide de Prévention $\mathrm{N}^{\circ} 4$ (Avril 2011): La Prévention des Risques Liés à l'Exposition au Bruit en Milieu Professionnel. Available at: http://www.isst.nat.tn/uploads/FCK files/br686410.pdf. Accessed: 2018-05-15

3. Chaib R. (2016): Pour un développement durable en santé et sécurité au travail dans les entreprises. Éditions Universitaire Européennes, ISBN 978-3-639-50803-1

4. Fuente A., Qiu W., Zhang M., Xie H., Kardous C.A., Campo P., Morata T.C. (2018): Use of the kurtosis statistic in an evaluation of the noise and solvent exposures on the hearing thresholds of workers: An exploratory study. The Journal of the Acoustical Society of America, Vol. 143, is. 3, p. 1704-1710, https://doi.org/10.1121/1.5028368

5. Scarwell H.-J., Roussel I., Charles L. (2013): Environnement et santé: quels enjeux, quels acteurs, quelle intelligibilité ? Développement durable \& territoires (on line), ISSN 1772-9971, Vol. 4, $\mathrm{n}^{\circ} 2$, https://journals.openedition.org/developpementdurable/9848. Accessed: 2018-06-01

6. Achte I., Delaflore, J.-L., Fabre C., Magny F., Songeur C. (2010): Comment concilier la performance et le bien-être au travail ? Mémoire MBA RH, Dauphine Université-Paris, p. 35.-36, https://mba-rh.dauphine.fr/fileadmin/ mediatheque/site/mba rh/pdf/Travaux anciens/Bien etre et la performance au travail.pdf

7. Organisation mondiale de la Santé (1991): Rapport du Groupe de travail informel sur la planification du Programme de prévention de la surdité et de la déficience auditive. https://apps.who.int/iris/bitstream/ handle/10665/61401/WHO PDH 91.1 fre.pdf? sequence=1\&isAllowed=y

8. Institut national de santé publique du Québec (2007): Le bruit en milieu de travail: une analyse des couts pour le régime d'indemnisation. https://www.inspq.qc.ca/pdf/publications/712-BruitMilieuTravail.pdf (Auteurs: Girard S.A., Picard M., Courteau M., Boisclair D., Larocque R., Leroux T., Turcotte F., Simard M.)

9. ***: Le bruit en milieu de travail. https://fr.scribd.com/document/288689881/Fiche-Bruit-Milieu-Travail

10. Institut National de Recherche et de Sécurité (2007): Moins fort le bruit. Édition INRS ED 6020. http://www.inrs.fr/dms/inrs/CataloguePapier/ED/TI-ED-6020/ed6020.pdf

11. Vincent B., Gissinger V. (2016): Les effets du bruit sur la santé. Révision 3, publié dans Bruit et Santé, Synthèse documentaire, No SIRET: 410118434 00027. http://www.acoucite.org/IMG/pdf/effets bruit-sante 2016.pdf

12. Gérard G., Jollois F.-X., Petiot J.-F., Qannari A., et al. (2012): Les logiciels et l'enseignement de la statistique dans les départements «Statistique et Informatique Décisionnelle» (STID) des IUT. Statistique et Enseignement, ISSN 2108-6745, 2(2), p. 5-24, https://hal.archives-ouvertes.fr/hal-00913110/document

13. Concha-Barrientos M., Campbell-Lendrum D., Steenland K. (2004): Occupational noise: Assessing the burden of disease from work-related hearing impairment at national and local levels. Geneva, World Health Organization. (WHO Environmental Burden of Disease Series, No. 9), https://www.who.int/quantifying ehimpacts/ publications/en/ebd9.pdf?ua=1

\section{Appendix 1}

Questionnaire form: 
Questionnaire on the impact of noise pollution on the health of workers

\section{Function:}

working time:

Age:

Sex: () Male () Female

Do you have hearing problems?

() Yes No

How long have you been exposed to noise? (Ie.

1) In general, you would say that your hearing is:

O Excellent () Very good () Good () Fair () Bad

2) Earlier audiometric tests:

() Yes No

3) Professional data:

3.1 - Function:

3.2 - Daily working hours:

C 3.3 - Working time in noisier units:

Which?

3.4 - Occupational noise exposure (noisy equipment)?

() Yes No

3.5 - Feeling sick a fter working in this noisy

environment

() Yes No

Total exposure time:

(Ie.

3.6 - Before this current job, you worked on

Very noisy place?
() Yes No

For how long? (Ie.

3.7 - Practice a noisy activity out of the file

working?

0 Yes No

How many times? (Ie.

4) Personal context:

4.1 - Earache

() Yes or? 0 OD 0 OE 0 Bilateral

() No

4.2 - Ear discharge:

0 Yes or? () OD 0 OE () Bilateral

0 No

() I do not know

4.3 - Do you take medication?

Yes ()

No ()

Which? (Ie.

4.4 - Have you noticed any changes in your hearing after a serious illness?

Yes ( )

No ()

What disease?

4.5 - Did you notice a difference in your hearing after

Did you take any medicine?

() Yes Which one? () Improved () worse

() No 
Questionnaire on the impact of noise pollution on the health of workers

4.6 - Ear surgery:

() Yes or? OOD 0 OE 0 Bilateral

O Do not know the side 0 No

5) you suffered a head trauma:

() Yes

() No

() I do not know

6) you suffered from acoustic trauma:

() Yes

() No

() I do not know

7) Someone in the family has a hearing problem:

0 Yes What kind of relationship?

() No

() I do not know

8) Vertigo:

0 Yes Evaluate your symptom: 0 Low () Medium O High

() No

9) Intolerance to loud sounds

() Yes Evaluate your symptom: 0 Low () Medium (0) High

() No

10) buzzing:

() Yes Evaluate your symptom: 0 Low () Medium () High

Which ear? () OD () OE 0 Bilateral

How many times?

Since when?.
() No

11) Headache:

0 Yes Evaluate your symptom: 0 Low 0 Medium 0 High

() No

12) Irritability:

0 Yes Evaluate your symptom: 0 Low () Medium 0 High

() No

13) Difficulty understanding the words:

0 Yes Evaluate your symptom: 0 Low () Medium () High

() No

14) Is it inattentive?

0 Yes Evaluate your symptom: 0 Low 0 Medium 0 High

0 No

15) Difficulty speaking in noisy environments:

() Yes Evaluate your symptom: () Low 0 Medium () High

( ) No

16) Sleep changes () Yes Evaluate your symptom: 0 low 0 average 0 high

() No 